University of Nebraska - Lincoln

DigitalCommons@University of Nebraska - Lincoln

Publications from USDA-ARS / UNL Faculty

U.S. Department of Agriculture: Agricultural

Research Service, Lincoln, Nebraska

2009

Diet $\mathrm{pH}$, and Viscosity Affect Development and Survival of

Screwworm Larvae (Diptera: Calliphoridae)

M. F. Chaudhury

USDA-ARS, muhammad.chaudhury@ars.usda.gov

Steven R. Skoda

University of Nebraska-Lincoln, sskoda1@unl.edu

Follow this and additional works at: https://digitalcommons.unl.edu/usdaarsfacpub

Part of the Agricultural Science Commons

Chaudhury, M. F. and Skoda, Steven R., "Diet pH, and Viscosity Affect Development and Survival of Screwworm Larvae (Diptera: Calliphoridae)" (2009). Publications from USDA-ARS / UNL Faculty. 788. https://digitalcommons.unl.edu/usdaarsfacpub/788

This Article is brought to you for free and open access by the U.S. Department of Agriculture: Agricultural Research Service, Lincoln, Nebraska at DigitalCommons@University of Nebraska - Lincoln. It has been accepted for inclusion in Publications from USDA-ARS / UNL Faculty by an authorized administrator of DigitalCommons@University of Nebraska - Lincoln. 


\title{
Diet pH, and Viscosity Affect Development and Survival of Screwworm Larvae (Diptera: Calliphoridae)
}

\author{
M. F. CHAUDHURY ${ }^{1}$ AND S. R. SKODA
}

USDA-ARS, Screwworm Research Unit. Panama City, Panama

\begin{abstract}
J. Econ. Entomol. 102(2): 799-803 (2009)
ABSTRACT The effects of dietary $\mathrm{pH}$ and viscosity on larval development of the New World screwworm, Cochliomyia hominivorax (Coquerel) (Diptera: Calliphoridae), were studied in the laboratory using a gel-based and a cellulose fiber-based media. The mean initial $\mathrm{pH}$ of the standard gelled diet was lower $(6.5 \pm 0.3)$ than that of the standard cellulose fiber-based diet $(6.8 \pm 0.6)$. As larval development progressed, these values decreased to below 6.0 possibly due to the accumulation of acidic metabolic waste. Diets formulated with higher initial $\mathrm{pH}(7.5)$ produced a slightly larger and greater number of pupae compared with those for untreated standard diets. The diets with lower than normal initial $\mathrm{pH}(4.0)$ produced significantly smaller and lower numbers of pupae compared with those produced by the untreated standard diets. The effects of viscosity were studied using the cellulose fiber-based diet at six different initial viscosity levels ranging from 2,000 to 7,000 cP. The viscosity level of the diet increased as the larval development progressed due to gradual loss of moisture from the diet. The diet viscosity levels of 4,000 and 5,000 $\mathrm{cP}$ proved superior for larval development showing significantly higher yield and larger pupae compared with those obtained from diets with initial viscosities of 2,000-3,000 or 6,000-7,000 cP. The cellulose fiber-based diet used for mass rearing should be formulated to an initial viscosity reading of $4,000-5,000 \mathrm{cP}$ for optimal larval growth and development. Adoption of a diet formulated to provide a higher initial $\mathrm{pH}$ such as 7.5 may produce better quality insects.
\end{abstract}

KEY WORDS Cochliomyia hominivorax, New World screwworm, mass rearing, eradication

Eradication programs for the new world screwworm, Cochliomyia hominivorax (Coquerel) (Diptera: Calliphoridae), by using the sterile insect technique are dependent on successful mass rearing of the insect. In turn, successful mass rearing is dependent on a successful rearing medium. The first mass rearing media of screwworm larvae depended on the use of beef and horsemeat. Later, a hydroponic media was developed followed by an artificial medium prepared from $6 \%$ spray-dried bovine blood, $5 \%$ spray-dried poultry eggs, and $4 \%$ milk substitute as the main dietary ingredients with $1.2 \%$ acrylamide-acrylate polymer gelling agents (Harris et al. 1984, Taylor et al. 1991). The current larval rearing medium uses the same dietary ingredients with $6 \%$ cellulose fiber as a bulking agent, and $0.1 \%$ formaldehyde solution as antimicrobial mixed in water (Chaudhury and Skoda 2007). The dietary ingredients provide all the essential dietary elements that are necessary for the developing insects as previously reported by Gingrich (1964). This larval diet

\footnotetext{
Mention of trade names or commercial products in this article is solely for the purpose of providing specific information and does not imply recommendation or endorsement by the U.S. Department of Agriculture.

${ }^{1}$ Corresponding author, e-mail: muhammad.chaudhury@ars.usda. gov.
}

is currently used to successfully mass rear 100 million flies weekly at the screwworm mass rearing plant in Tuxtla Gutierrez, Chiapas, Mexico.

Although the current artificial larval diet produces quality insects (Chaudhury and Skoda 2007), additional research was conducted to study the effects of the diet $\mathrm{pH}$ and viscosity on larval development and to determine whether improvements of the diet can be made by manipulating these characteristics. Generally, the $\mathrm{pH}$ range of foods that are palatable or preferred by insects is within a fairly narrow scale: $\approx 2 \mathrm{pH}$ points or sometimes less. Various factors that are $\mathrm{pH}$ related in insect diet are palatability, texture, modification of flavors of the individual nutrients, extent of the stability of diet in relation to microbial contaminants, and enzyme function (Zeng and Cohen 2002, Cohen 2004). For a semiliquid diet such as of screwworm larvae, the correct viscosity is important to provide correct texture for the larvae to move about without drowning and at the same time to be able to ingest dissolved and particulate nutrients from the medium.

Previous observations indicated that during the normal course of screwworm larval development on the artificial diet, the initial $\mathrm{pH}$ of $\approx 6.8$ decreases to $\approx 4.7$ (M.F.C., unpublished data). This is probably due to 
accumulation of acidic metabolites, resulting from microbial activities in the medium. Also, the viscosity of the previously used gelled diet was routinely checked and was found to hold between 4,500 and 5,000 cP during larval growth (M.F.C., unpublished data). However, the effects of diet $\mathrm{pH}$ and viscosity on the development of screwworm indicated by life-history parameters have not been studied previously. When developing new diets or making improvements to the existing ones, diet $\mathrm{pH}$ and viscosity have been checked routinely for uniformity of the diet batches, but data were never reported. Consequently, the current research was conducted on the $\mathrm{pH}$ and viscosity of the screwworm larval medium to determine their effects on overall life history parameters on the insects reared. Herein, for general comparison of the two bulking agents, we report the normal $\mathrm{pH}$ of cellulose fiber-based and gel-based diets and the effects of changing the $\mathrm{pH}$ through the larval developmental period, the viscosity of the cellulose fiber-based diet, and the effects of changing the viscosity on larval development.

\section{Materials and Methods}

Insects and Diet Materials. The tests were conducted using the same screwworm strain and general diet preparation procedures as described by Chaudhury and Skoda 2007.

Study of Diet pH. Tests were conducted using both cellulose fiber-based and gelled diets. Diet batches were prepared fresh each day. Each larval rearing tray ( 25.5 by 18.5 by $9.5 \mathrm{~cm}$ in depth) received an initial 300 $\mathrm{ml}$ of the diet (day 0$)$. One hundred milligrams of eggs $(\approx 2,000$ eggs) on a piece of moist paper towel ( 3 by $3 \mathrm{~cm}$ ) was placed on top of the medium. Six hundred milliliters of diet was added on days 2 and 3 . The $\mathrm{pH}$ of the diet was measured using a hand-held Extech waterproof digital $\mathrm{pH}$ tester for semiliquid-semisolid substances (Daigger Laboratory Equipment Supplies; www.daigger.com). Five $\mathrm{pH}$ readings were taken (each corner and center of the tray), and an average was calculated for each tray. The $\mathrm{pH}$ readings were taken, starting on day 0 just before seeding of eggs and every $24 \mathrm{~h}$ thereafter during the entire larval development. On day 2 and 3 readings were taken twice, once before and once after the addition of the diet ration. Most of the mature third instars crawled out of the media on day 5 and dropped onto sawdust $(2 \mathrm{~cm}$ in depth) provided in a pan (28 by 24 by $13 \mathrm{~cm}$ in depth) held under each tray, where pupation occurred. On day 5, a sample of 100 larvae was randomly taken from each tray and weighed. Five days after pupation, pupae from each tray were sifted from the sawdust and weighed. At the same time, a sample of 100 pupae was taken randomly from each tray and weighed. The total number of pupae was determined by dividing the total weight with the weight of 100 pupae. One hundred pupae from each tray were held in small cages, adults emerged, and percentage emergence was recorded. Adult longevity was determined by holding 100 newly emerged flies in cages with honey and water and recording their mortality until $50 \%$ of the flies survived. To determine fecundity, 200 mated females from each tray were held in a cage with a diet of honey mixed with spray-dried egg (Chaudhury et al. 2000) and a separate container for water. When the females were $7 \mathrm{~d}$ old, a petri dish with $50 \mathrm{mg}$ of cellulose fiber mixed with $5 \mathrm{ml}$ of diet waste liquid (as oviposition attractant) was introduced into the cage to induce oviposition. After allowing $3 \mathrm{~h}$ for oviposition, the petri dish was removed from the cage and the egg batches were collected and weighed. To determine fertility, two samples of $50 \mathrm{mg}$ of eggs from each test were placed in petri dishes lined with moist filter paper and incubated at $38 \pm 1^{\circ} \mathrm{C}$ for $\approx 20 \mathrm{~h}$. Unhatched eggs and egg shells from each petri dish were collected, counted under a microscope $(10 \times$ magnification), and percentage of hatch was determined.

Similar tests were conducted to determine a range of $\mathrm{pH}$ in which larvae would successfully develop. The $\mathrm{pH}$ of the diet was adjusted using either one molar solution of $\mathrm{NaOH}$ to provide an initial $\mathrm{pH}$ of $7.5(0.7$ higher than the initial $\mathrm{pH}$ of 6.8) or using $1 \mathrm{M}$ solution of crystalline citric acid $\left(\mathrm{C}_{6} \mathrm{H}_{8} \mathrm{O}_{7}\right)$ to provide an initial acidic $\mathrm{pH}$ of 4.0 ( 0.7 lower than the observed lowest $\mathrm{pH}$ of 4.7 on day 5 of larval development). The $\mathrm{pH}$ level was again adjusted to the same level by mixing the appropriate amount of $\mathrm{NaOH}$ or citric acid solution to each batch of the new diet that was added on day 2 and 3 of the larval development; no pH adjustments were made on days 1, 4 or 5 . Each test was replicated four times.

Study of Diet Viscosity. Tests were conducted using cellulose fiber-based diets. Trays of diets were set up and general methods were as described above. Two samples (200 ml each) of each batch of the freshly prepared diets were used to measure viscosity using a Cole Parmer medium range rotational viscometer with \#7 spindle (Cole Parmer, Vernon Hills, IL), and the average of two readings was recorded. Diets were prepared by adjusting volume of water and the bulking agent (cellulose fiber) to obtain diet batches with viscosity readings ranging from 2,000 to $7,000 \mathrm{cP}$. Viscosity readings were taken every $24 \mathrm{~h}$ during the entire larval developmental period, except on day 2 and 3 when two readings were taken, once before and once after the fresh diet was added. The $\mathrm{pH}$ readings of the diet also were recorded to ascertain uniformity within tests. One hundred milligrams of eggs $(\approx 2,000$ eggs $)$ were placed in each tray. Larval and pupal weights and the number of pupae were recorded from each tray as described above. Percentage biological yield was determined by dividing the number of pupae obtained by the expected number $(2,000)$ and multiplying by 100. Each test was replicated four times.

Statistics. Repeated measures analysis (SAS Institute 2005) was used to evaluate $\mathrm{pH}$ values between cellulose fiber-based and gelled diets over the larval development time of $5 \mathrm{~d}$ (measurements taken after adding diet, shown as $2 \mathrm{~b}$ and $3 \mathrm{~b}$ in Fig. 1, were not used). Multivariate analysis of variance (ANOVA) was used to examine response variables of larval 


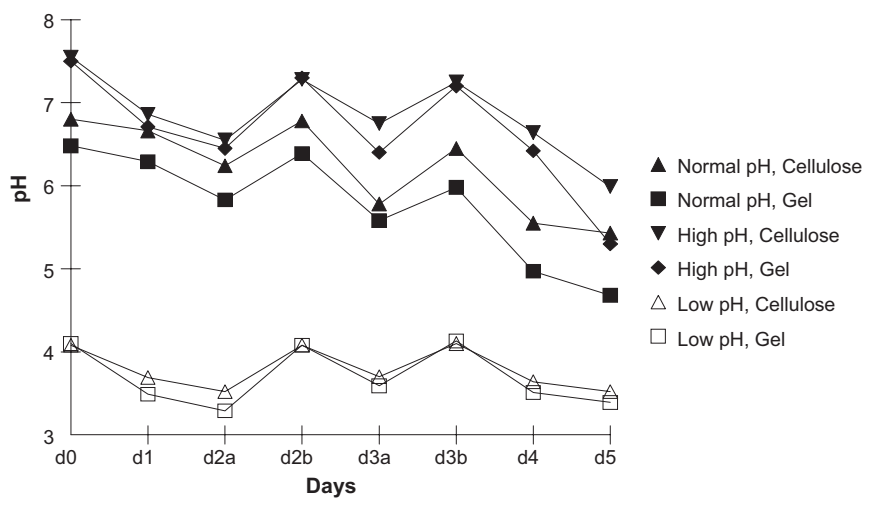

Fig. 1. Mean $\mathrm{pH}$ readings of the diets during screwworm larval development. On the second and third days, $\mathrm{pH}$ readings were taken before adding diet ( $\mathrm{d} 2 \mathrm{a}$ and $\mathrm{d} 3 \mathrm{a}$, respectively) and after adding diet ( $\mathrm{d} 2 \mathrm{~b}$ and $\mathrm{d} 3 \mathrm{~b}$, respectively).

weight, pupal weight, number of pupae, adult emergence, total egg weight, hatching of eggs, and adult longevity for cellulose fiber-based and gelled diets at each level of pH adjustment: Tukey's honestly significant difference (HSD) test was used to separate means (SAS Institute 2005). Data from viscosity tests were statistically evaluated with one-way ANOVA followed by Tukey's multiple range test to separate means after a significant $F$ value (Sokal and Rohlf 1981, NCSS 2000).

\section{Results}

Diet pH. The initial pH of normal, nonadjusted, cellulose fiber-based diet was higher $(6.8 \pm 0.6)$ than the normal gelled diet $(6.5 \pm 0.3)$. The $\mathrm{pH}$ of both the diets declined gradually during the 5-d larval developmental period; however, this decline was interrupted when fresh diet aliquots were added to the trays at regular intervals when $\mathrm{pH}$ was elevated almost to the initial readings (Fig. 1). The mean $\mathrm{pH}$ range for the cellulose fiber-based diet over the $5 \mathrm{~d}$ was from 6.8 to 5.3 , whereas that of the gelled diet was from 6.5 to 4.7; this difference between diets was statistically significant by days $(F=1266.01 ; \mathrm{df}=5,80 ; P \leq 0.0001)$ and days between treatments $(F=21.13$; df $=5,80$; $P \leq 0.0001)$. The $\mathrm{pH}$ ranges for both diets were suitable for larval growth and development as shown by similar, but statistically different larval and pu- pal weights, life history parameters in both diets (Table 1).

When $\mathrm{pH}$ was adjusted to provide a lower initial $\mathrm{pH}$ of 4.0, the $\mathrm{pH}$ during larval development ranged from 4.0 to 3.5 for the cellulose fiber-based diet and from 4.1 to 3.4 for the gelled diet (Fig. 1). These diets resulted in significantly lower larval and pupal weights, number of pupae, percentage of adult emergence, and amount of eggs laid compared with those parameters obtained from the diets with normal or higher than normal $\mathrm{pH}$ (Table 1). These low values are unacceptable for the eradication program; therefore, further analysis was not done.

When the $\mathrm{pH}$ of both the diets was adjusted to provide a higher initial $\mathrm{pH}$ of 7.5 , the $\mathrm{pH}$ range during the developmental period was from 7.5 to 6.0 for the cellulose fiber-based diet and from 7.5 to 5.3 for the gelled diet (Fig. 1); this difference between diets was statistically significant, for each day $(F=825.2$; df $=$ $5,80 ; P \leq 0.0001)$ and days within treatment after day 0 (initial day of $\mathrm{pH}$ adjustment) $(F=19.7$; $\mathrm{df}=5,80$; $P \leq 0.0001)$. Considering means for both bulking agents, there was significantly higher larval weight $(F=209.4 ; \mathrm{df}=2,45 ; P \leq 0.0001)$ and pupal weight $(F=413.7$; $\mathrm{df}=2,45 ; P \leq 0.0001)$ at the higher $\mathrm{pH}$. The other biological parameters were not significantly different.

Generally, biological parameters were significantly higher for the cellulose fiber than for the gelled diets

Table 1. Life history parameters (mean \pm SD) of screwworm reared on cellulose fiber-based and gelled diets of with normal and controlled pH

\begin{tabular}{|c|c|c|c|c|c|c|}
\hline \multirow{2}{*}{ Parameter $(F, P)$} & \multicolumn{3}{|c|}{ Cellulose fiber-based diet } & \multicolumn{3}{|c|}{ Gel-based diet } \\
\hline & Normal pH & Higher pH & Lower pH & Normal pH & Higher pH & Lower $\mathrm{pH}$ \\
\hline Larval wt, mg $\left(62.7^{a}, 0.00\right)$ & $68.8 \pm 1.1 b$ & $71.8 \pm 1.3 \mathrm{a}$ & $51.6 \pm 3.3 \mathrm{~d}$ & $60.8 \pm 2.6 c$ & $63.3 \pm 09 b$ & $53.8 \pm 2.1 \mathrm{~d}$ \\
\hline Pupal wt, mg $\left(227.1^{a}, 0.00\right)$ & $52.8 \pm 1.4 \mathrm{~b}$ & $54.6 \pm 1.6 \mathrm{a}$ & $33.8 \pm 1.3 \mathrm{~d}$ & $43.2 \pm 1.4 \mathrm{c}$ & $44.4 \pm 0.7 \mathrm{c}$ & $34.2 \pm 0.8 \mathrm{~d}$ \\
\hline No. pupae/tray $\left(43.4^{a}, 0.00\right)$ & $1677 \pm 110 \mathrm{~b}$ & $1742 \pm 114 \mathrm{a}$ & $1198 \pm 129 c$ & $1602 \pm 52 b$ & $1670 \pm 92 b$ & $957 \pm 183 \mathrm{c}$ \\
\hline$\%$ emergence $\left(21.8^{a}, 0.00\right)$ & $94.5 \pm 0.6 \mathrm{a}$ & $95.8 \pm 1.1 \mathrm{a}$ & $86.2 \pm 3.2 b$ & $95.3 \pm 0.9 \mathrm{a}$ & $94.8 \pm 2.1 \mathrm{a}$ & $84.5 \pm 3.5 b$ \\
\hline Eggs laid, g $\left(16.9^{a}, 0.00\right)$ & $4.5 \pm 0.5 \mathrm{a}$ & $4.2 \pm 0.9 \mathrm{a}$ & $1.9 \pm 0.6 b$ & $4.2 \pm 0.7 \mathrm{a}$ & $4.3 \pm 0.7 \mathrm{a}$ & $1.8 \pm 0.9 b$ \\
\hline$\%$ eggs hatch $(1.1,0.38)$ & $91.4 \pm 1.9 \mathrm{a}$ & $90.1 \pm 3.8 \mathrm{a}$ & $88.5 \pm 5.4 \mathrm{a}$ & $93.5 \pm 4.7 \mathrm{a}$ & $90 \pm 3.6 \mathrm{a}$ & $87.2 \pm 2.2 \mathrm{a}$ \\
\hline Longevity, $\mathrm{d}\left(3.0^{a}, 0.04\right)$ & $12.3 \pm 2.6 \mathrm{ab}$ & $13 \pm 1.8 \mathrm{ab}$ & 10. $\pm 0.9 \mathrm{c}$ & $15 \pm 3.1 \mathrm{a}$ & $14.5 \pm 2.5 \mathrm{ab}$ & $12.8 \pm 1.1 \mathrm{ab}$ \\
\hline
\end{tabular}

${ }^{a}$ Means \pm SD for each parameter followed by different letters are significantly different by Tukey’s HSD test. 


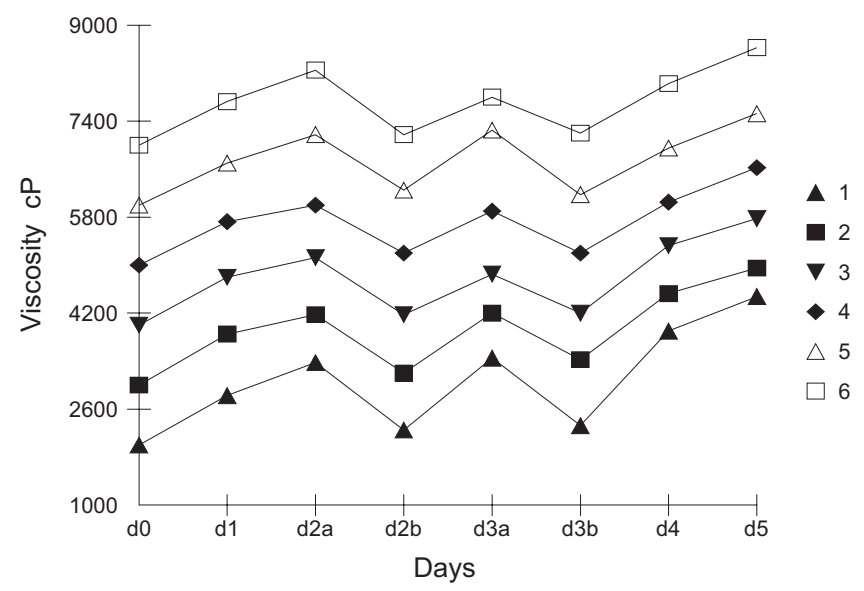

Fig. 2. Mean viscosity readings of the cellulose fiber-based diets during screwworm larval development. Lines showing indicated initial viscosity: $1,2,000 ; 2,3,000 ; 3,4,000 ; 4,5,000 ; 5,6,000$; and $6,7,000$. Days for viscosity readings are as in Fig. 1.

(Table 1). Statistical analysis of the difference in values for cellulose fiber-based diet at the higher (adjusted to 7.5) versus normal, nonadjusted $\mathrm{pH}$ showed significantly higher values for the higher $\mathrm{pH}$ of larval weights $(F=36.6$; df $=1,22 ; P \leq 0.0001)$, pupal weights $(F=23.8$; df $=1,22 ; P \leq 0.002)$ and number of pupae $(F=4.4$; $\mathrm{df}=1,22 ; P \leq 0.05)$.

Diet Viscosity. The initial viscosity readings of six different cellulose fiber-based diets were adjusted to $2,000,3,000,4,000,5,000,6,000$, and 7,000 cP. This viscosity increased with time, except when additional diet aliquots were mixed on day 2 and 3, resulting in a temporary decrease in viscosity, ultimately reaching to a viscosity of $4,475 \pm 193.11,5,000 \pm 108.01,5,800 \pm$ $91.29,6625 \pm 103.08,8,100 \pm 248.33$, and 8,625 \pm 75 , respectively, on day 5 when most of the larvae crawled off for pupation (Fig. 2). Larval weight, pupal weight, and number of pupae per tray from the diets with the two lower viscosities were significantly lower than those obtained from the two diets mid-range in viscosity (Table 2 ). The same parameters obtained from the insects reared in two diets with higher viscosity range were also significantly lower than those obtained from two diets with mid-range viscosity but slightly higher, although not significantly, than those obtained from the two diets with lower viscosity (Table 2 ). The only exception to this was the significantly lower number of pupae from the diet with the lowest viscosity compared with the numbers obtained from all other diets.

\section{Discussion}

The $\mathrm{pH}$ of an artificial diet for an insect is extremely important for several reasons. The $\mathrm{pH}$ influences most chemical reactions involving digestive enzymes in the gut; the $\mathrm{pH}$ also regulates the flavor, palatability and texture of a diet (Cohen 2004). In addition, the $\mathrm{pH}$ may be responsible for regulating microbial action on the prepared diet. The $\mathrm{pH}$ of wounds of animals infested with screwworms has been reported earlier by Laake and Smith (1938). They showed that the mean $\mathrm{pH}$ of wounds of guinea pigs, goats, and sheep exhibited a significant increase in alkalinity (7.5) on the third day of the infestation, but decreases gradually to below 7.0 by the seventh day of infestation. During the postinfestation period, the mean $\mathrm{pH}$ of the wounds changed to the acid side $(\approx 6.5)$ in the animals that survived (Laake and Smith 1938).

The results presented here clearly indicate that the screwworm larvae can grow and develop normally on a diet having a fairly wide range of $\mathrm{pH}$ (from 7.5 to 5.0). Increasing the initial diet $\mathrm{pH}$ to 7.5 from the normal initial pH of 6.5 resulted in production of significantly larger larvae and pupae, suggesting that maintaining a diet $\mathrm{pH}$ that more closely mimics that of infested

Table 2. Life history parameters (mean \pm SD) of screwworm reared on cellulose fiber-based diet of varying viscosity

\begin{tabular}{|c|c|c|c|c|c|c|}
\hline \multirow{2}{*}{ Parameter $(F, P)$} & \multicolumn{6}{|c|}{ Initial diet viscosity, $\mathrm{cP}$} \\
\hline & 2,000 & 3,000 & 4,000 & 5,000 & 6,000 & 7,000 \\
\hline Larval wt, mg $\left(34.7^{a}, 0.00\right)$ & $56.9 \pm 2.9 \mathrm{c}$ & $58.2 \pm 2.2 \mathrm{c}$ & $71.9 \pm 1.7 \mathrm{a}$ & $70.6 \pm 1.9 \mathrm{a}$ & $62.2 \pm 3.4 \mathrm{~b}$ & $56.2 \pm 1.5 \mathrm{c}$ \\
\hline Pupal wt, mg $\left(27.9^{a}, 0.00\right)$ & $34.4 \pm 2.4 \mathrm{c}$ & $35.3 \pm 1.2 \mathrm{c}$ & $54.5 \pm 0.8 \mathrm{a}$ & $53.7 \pm 1.7 \mathrm{a}$ & $42.9 \pm 8.1 b$ & $34.1 \pm 1.3 \mathrm{c}$ \\
\hline No. pupae/tray $\left(41.1^{a}, 0.00\right) 747$ & $747 \pm 107 \mathrm{c}$ & $1,082 \pm 141 b$ & $1,717 \pm 144 \mathrm{a}$ & $1,628 \pm 88 \mathrm{a}$ & $1,104 \pm 106 b$ & $1,008 \pm 124 b$ \\
\hline$\%$ biological yield & 37 & 54 & 86 & 81 & 55 & 50 \\
\hline
\end{tabular}

${ }^{a}$ Means \pm SD for each parameter followed by different letters are significantly different by Tukey's multiple range test. The pH for diet (mean $\pm \mathrm{SD}$ ) over study period: day $0,6.85 \pm 0.05$; day $1,6.43 \pm 0.22$; day $2 \mathrm{a}, 5.95 \pm 0.13$; day $2 \mathrm{~b}, 6.80 \pm 0.01$; day $3 \mathrm{a}, 6.23 \pm 0.15$; day $4,6.05 \pm$ 0.13 ; day $5,5.73 \pm 0.18$. 
animals may prove useful in producing larger and healthier insects under the mass rearing conditions. When the initial diet $\mathrm{pH}$ was changed to 4.0, growth and development of the larvae were severely affected, showing significantly lower survival and lower pupal weight. Obviously, screwworm larvae are unable to tolerate a diet $\mathrm{pH}$ so low on the acidic scale. Similar research on Mediterranean fruit fly, Ceratitis capitata (Wiedmann) (Diptera: Tephritidae), shows that the optimal larval development occurs at diet $\mathrm{pH}$ between 5.0 and 5.5 and the pupal yield was highest between 3.2 and 5.5 (Chan and Jang 1995). A diet pH of 6.0 or higher was found to reduce pupal survival in C. capitata (Chan and Jang 1995). Maintenance of $\mathrm{pH}$ at 5.0 in larval diet of this insect resulted in a significant improvement in overall yield $(>20 \%)$ over diets in which the $\mathrm{pH}$ was not controlled (Chan and Jang 1995). Obviously, the optimum $\mathrm{pH}$ level of the diet required by the Mediterranean fruit fly, a phytophagous insect, is considerably different than the need of the screwworm, a zoophagous insect. However, the general range of $\mathrm{pH}, \approx 2.0 \mathrm{pH}$ points, tolerated by screwworms is similar to that of Mediterranean fruit fly. More research will be needed, especially the effects of various buffer chemicals that resist changes in $\mathrm{pH}$ to determine the importance of regulating diet $\mathrm{pH}$ to obtain optimal growth and development of insects.

The viscosity of a diet provides the diet texture which is an important aspect of an artificial diet to impart palatability and stability of the diet (Cohen 2004). In screwworm diet, as viscosity increases $(>6,000 \mathrm{cP})$, the medium becomes thicker and the ingestion of the nutrients becomes increasingly more difficult for the larvae; alternatively, a decrease in viscosity $(<4,000 \mathrm{cP})$ results a semiliquid diet causing larvae to exhibit increased locomotor activity. In a low viscosity medium, the developing larvae move about rapidly and do not seem to be able to ingest the dissolved or suspended nutrient particles sufficiently to maintain normal growth. Results presented here clearly indicate that the initial diet viscosity of 4,000 and $5,000 \mathrm{cP}$ is optimum for producing insects of acceptable size and quantity. Adoption of a diet formulated to this viscosity and to an initial $\mathrm{pH}$ of 7.5 could produce better quality insects for current and future needs of eradication and exclusion programs against $C$. hominivorax.

\section{Acknowledgments}

The technical assistance of Celia Jimenez, Lupita Hernandez, and Luis Lopez is gratefully acknowledged. We thank Dennis R. Berkebile and Donald B. Thomas, USDA-ARS, for critical review of the manuscript.

\section{References Cited}

Chan, H. T., Jr., and E. B. Jang. 1995. Diet pH effects on mass rearing of Mediterranean fruit fly (Diptera: Tephritidae). J. Econ. Entomol. 88: 569-573.

Chaudhury, M. F., L. A. Alvarez, and L. S. Velásquez. 2000. A new meatless diet for adult screwworm (Diptera: Calliphoridae). J. Econ. Entomol. 93: 1398-1401.

Chaudhury, M. F., and S. R. Skoda. 2007. A cellulose fiberbased diet for screwworm (Diptera: Calliphoridae) larvae. J. Econ. Entomol. 100: 241-245.

Cohen, A. C. 2004. Insect diets: science and technology. CRC, Boca Raton, FL.

Gingrich, R. E. 1964. Nutritional studies on screwworm larvae with chemically defined media. Ann. Entomol. Soc. Am. 57: 351-360.

Harris, R. L., R. D. Peterson III, M. E. Vazquez-Guvara, and O. H. Graham. 1984. Gelled media for the production of screwworm larvae. Southwest. Entomol. 9: 257-262.

Laake, E. W., and C. L. Smith. 1938. The hydrogen ion concentration of myiotic wounds in sheep and goats. J. Econ. Entomol. 31: 441-443.

[NCSS] Number Cruncher Statistical System. 2000. NCSS statistical system for Windows, user manual version 6 . Number Cruncher Statistical System, Kaysville, UT.

SAS Institute. 2005. SAS user's guide: statistics, version 9.1.3. SAS Institute, Cary, NC.

Sokal, R. R., and F. J. Rohlf. 1981. Biometry. Freeman, New York.

Taylor, D. B., J. C. Bruce, and R. Garcia. 1991. Gelled diet for screwworm (Diptera: Calliphoridae) mass production. J. Econ. Entomol. 84: 927-935.

Zeng, F. Y., and A. C. Cohen. 2002. Partial characterization of a-amylase in the salivary glands of Lygus hesperus and L. lineolaris. Comp. Biochem. Physiol. 126: 9-16.

Received 23 July 2008; accepted 18 December 2008. 